\title{
Effect of neuroleptic treatment on involuntary movements and motor performances in Huntington's disease
}

\author{
F GIROTTI, F CARELLA, G SCIGLIANO, MP GRASSI, P SOLIVERI, P GIOVANNINI, \\ E PARATI, T CARACENI
}

From the Department of Neurology, Istituto Neurologico “C. Besta”, Milan, Italy

SUMMARY Eighteen patients with Huntington's chorea were examined before and after neuroleptic treatment (haloperidol, pimozide, tiapride) to study the effect of such treatment on hyperkinesia and motor performance. Pimozide and haloperidol improved hyperkinesia; none of the drugs significantly affected motor performance. No correlation was found between the severity of hyperkinesia and motor performance scores, or between hyperkinesia and intelligence score, before and after therapy.

Abnormal involuntary movements are a most distinctive clinical aspect of Huntington's disease. Striatal dopaminergic hyperactivity is supposed to cause abnormal involuntary movements in Huntington's disease.' Neuroleptic drugs, which act by inhibiting dopaminergic transmission at the synaptic level, ${ }^{2}$ are the accepted current therapy of abnormal involuntary movements in Huntington's disease. ${ }^{3}$ Their effect upon abnormal involuntary movements has been evaluated semiquantitatively. ${ }^{4-7}$ Impairment of motor performance ${ }^{589}$ and functional disability' are other aspects of Huntington's disease. These features have scarcely been considered in relation to neuroleptic treatment, since attention has been focused by different authors on hyperkinesia. Shoulson ${ }^{7}$ has observed that functional capacities of choreics were not influenced by neuroleptics. The relationship between abnormal involuntary movements and motor ability should be considered in this context.

The aim of our study was to verify (1) the possible correlation between abnormal involuntary movements and motor impairment in Huntington's disease and (2) the effect of neuroleptic drugs on the same parameters.

Address for reprint requests: Dr T Caraceni, Dept. of Neurology, Istituto Neurologico "C. Besta", via Celoria 11, 20133 Milano, Italia.

Received 11 October 1983 and in revised form 9 January 1984. Accepted 10 January 1984

\section{Materials and methods}

Eighteen choreic patients, all showing typical abnormal involuntary movements, mental deterioration and with a family history, were examined. No psychotic disturbances were observed in any patient during the study. Informed consent to enter the pharmacological trial was obtained from each patient. Fourteen age- and education-matched normal subjects served as controls in the tests of intelligence and motor performance. Mean age of the patients with Huntington's disease ( 11 males, 7 females) was 43.9 years (range $31-59$ ); mean disease duration was 4.7 years (range 1-9). Mean age of control subjects ( 5 males, 9 females) was 39.9 years (range 28-59).

Pimozide, haloperidol and tiapride were used in the pharmacological trial at the dosages reported in table 1 , which also gives the number of patients treated with each drug. Each pharmacological trial lasted one month. When a patient was given more than one neuroleptic drug, each drug was given singly and successively, with a 15-day washout period in between. Patients evaluated in the basal condition were either patients who had never been treated with neuroleptic drugs (seven patients) or patients already treated in the past with such drugs but who had been free of therapy for at least one month before the basal evaluation.

The evaluation of the subjects included the following tests: (1) The Wechsler adult intelligence scale (WAIS), (2) The tapping test: each subject had to press the key of a laboratory counter (Clay Adams, Parsinappy, NY) with both his right and left forefinger. Each session consisted of three trials of $10 \mathrm{~s}$ each, separated by an interval of $10 \mathrm{~s}$ for each hand. The total number of tappings was recorded, (3) The Gibson spiral maze was given and scored, according to Pattie and Gilleard. ${ }^{10}$ (4) The screw-and-nut test: each subject had to screw three nuts on their respective screws, 
Table 1 Drug treatment in Huntington's disease patients

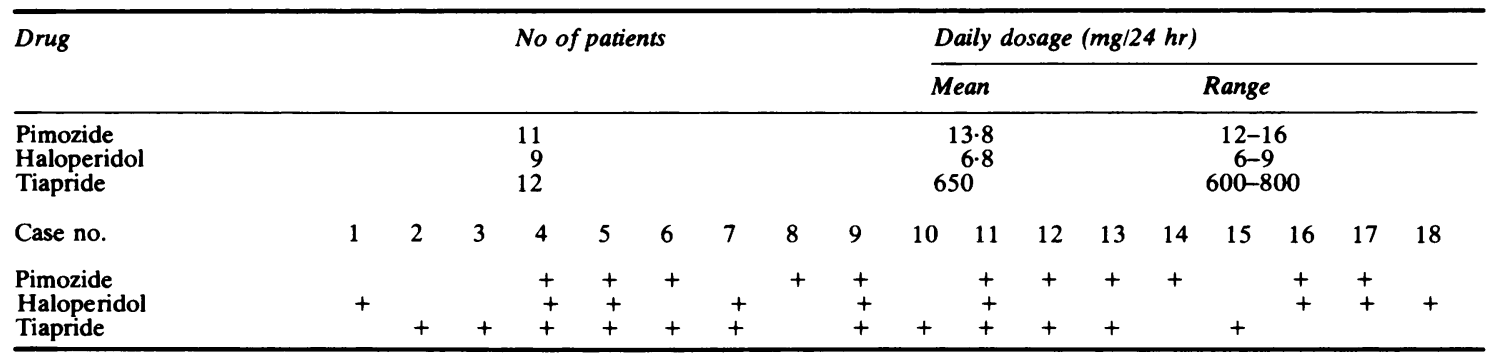

and the time in seconds to complete the task was recorded (5) Number of abnormal involuntary movements: three examiners counted the abnormal involuntary movements when the patient was in the sitting position. A single body area (head and face, trunk, upper limbs, lower limbs) was examined for a period of $2 \mathrm{~min}$. The mean of the three observations was scored for each area and added to those of the other areas. Subjects were evaluated before the beginning of treatment and at the end of each treatment period. The WAIS test was given only in the basal condition.

Statistical analysis included Student's $t$ test and $\mathrm{r}$ correlation coefficient.

\section{Results}

In the control group, there was a correlation among the motor performance test scores, whereas the
WAIS score did not correlate with any of the motor performance test scores (table 2).

In the basal condition, the screw-and-nut test score of choreics was correlated with the Gibson score and the WAIS score. None of the motor ability test scores or the WAIS score correlated with the severity of abnormal involuntary movements. The WAIS total score was lower in Huntington's disease patients (mean IQ $=76$ ) than in control subjects (mean IQ $=102 ; p<0.001$ ). In the basal condition, mean scores of the tapping test (Huntington's disease patients 54.4 ; control subjects, 103.1 ; p < 0.001), of the Gibson spiral maze (Huntington's disease patients, 8.4; control subjects, $11 ; p<0.01$ ), and of the screw and nut test (Huntington's disease patients, 125; control subjects, $52.6 ; \mathrm{p}<0.01)$ were

Table 2 Correlation coefficients between different motor tests, abnormal involuntary movements and WAIS

\begin{tabular}{|c|c|c|c|c|c|c|c|c|c|c|c|}
\hline \multirow[t]{2}{*}{ Test } & \multicolumn{4}{|c|}{ Huntington's disease free } & \multicolumn{4}{|c|}{ Huntington's disease best treatment } & \multicolumn{3}{|c|}{ Control subjects } \\
\hline & Tap & Screw & Gibson & WAIS & Tap & Screw & Gibson & WAIS & Tap & Screw & Gibson \\
\hline $\begin{array}{l}\text { Screw } \\
\text { Gibson } \\
\text { WAIS } \\
\text { AIMs }\end{array}$ & $\begin{array}{r}-0.43 \\
0.23 \\
0.10 \\
-0.16\end{array}$ & $\begin{array}{c}-0.63^{*} \\
-0.56 \ddagger \\
0.06\end{array}$ & $\begin{array}{l}0.36 \\
0.19\end{array}$ & -0.25 & $\begin{array}{c}-0.77^{*} \\
0.73^{*} \\
0.56 \ddagger \\
-0.29\end{array}$ & $\begin{array}{r}-0.84^{*} \\
-0.41 \\
0.08\end{array}$ & $\begin{array}{r}0.31 \\
-0.05\end{array}$ & $-0 \cdot 29$ & $\begin{array}{c}-0.54 \dagger \\
0.54 \dagger \\
0.31\end{array}$ & $\begin{array}{l}-0.49 t \\
-0.03\end{array}$ & $0 \cdot 14$ \\
\hline
\end{tabular}

${ }^{*} \mathrm{p}<0.001$

$+\mathrm{p}<0.05$.

$\neq \mathrm{p}<0.02$.

Table 3 Scores obtained before and after treatment

\begin{tabular}{|c|c|c|c|c|c|c|}
\hline & \multicolumn{2}{|c|}{ Pimozide $(n=11)$} & \multicolumn{2}{|c|}{ Haloperidol $(n=9)$} & \multicolumn{2}{|c|}{ Tiapride $(n=12)$} \\
\hline & Before & After & Before & After & Before & After \\
\hline $\begin{array}{l}\text { Tapping } \\
\text { Mean } \\
\text { SD } \\
\text { Gibson }\end{array}$ & $\begin{array}{l}54 \cdot 50 \\
27 \cdot 27\end{array}$ & $\begin{array}{l}51 \cdot 36 \\
20 \cdot 83\end{array}$ & $\begin{array}{l}62 \cdot 51 \\
23 \cdot 86\end{array}$ & $\begin{array}{l}49 \cdot 34 \\
18 \cdot 24\end{array}$ & $\begin{array}{l}60 \cdot 42 \\
24 \cdot 42\end{array}$ & $\begin{array}{l}56.04 \\
20.78\end{array}$ \\
\hline $\begin{array}{l}\text { Mean } \\
\text { SD } \\
\text { Screw-\&-nut }\end{array}$ & $\begin{array}{r}9 \cdot 00 \\
2 \cdot 60\end{array}$ & $\begin{array}{r}9.45 \\
2.69\end{array}$ & $\begin{array}{r}9 \cdot 25 \\
3 \cdot 37\end{array}$ & $\begin{array}{l}9 \cdot 12 \\
3 \cdot 44\end{array}$ & $\begin{array}{l}8 \cdot 91 \\
2 \cdot 50\end{array}$ & $\begin{array}{l}9 \cdot 33 \\
2 \cdot 46\end{array}$ \\
\hline $\begin{array}{l}\text { Mean } \\
\text { SD } \\
\text { AIMs }\end{array}$ & $\begin{array}{r}116 \cdot 81 \\
63 \cdot 23\end{array}$ & $\begin{array}{l}135 \cdot 63 \\
114.48\end{array}$ & $\begin{array}{r}115.55 \\
56.80\end{array}$ & $\begin{array}{r}124.44 \\
71.67\end{array}$ & $\begin{array}{r}129.41 \\
84.71\end{array}$ & $\begin{array}{r}112.66 \\
58 \cdot 53\end{array}$ \\
\hline $\begin{array}{l}\text { Mean } \\
\text { SD }\end{array}$ & $\begin{array}{l}393 \cdot 36 \\
255 \cdot 51 \\
\end{array}$ & $\begin{array}{l}241.45^{*} \\
252.22\end{array}$ & $\begin{array}{l}311 \cdot 22 \\
285 \cdot 09\end{array}$ & $\begin{array}{l}131 \cdot 00^{\dagger} \\
141.26\end{array}$ & $\begin{array}{l}371.08 \\
251 \cdot 82\end{array}$ & $\begin{array}{l}299 \cdot 83 \\
234 \cdot 89 \\
\end{array}$ \\
\hline
\end{tabular}

${ }^{*} \mathrm{p}<0.01$

$+\mathrm{p}<0.05$. 
Table 4 Test scores of 18 choreic patients before treatment and after best treatment

\begin{tabular}{|c|c|c|c|c|c|c|c|c|c|c|}
\hline \multirow[t]{2}{*}{ No } & \multicolumn{4}{|c|}{ Before treatment } & \multicolumn{4}{|c|}{ Best treatment* } & \multirow[t]{2}{*}{ Drug } & \multirow[t]{2}{*}{ Side effects } \\
\hline & Tap & Screw & Gibson & AIMS† & Tap & Screw & Gibson & AIMs† & & \\
\hline $\begin{array}{r}1 \\
2 \\
3 \\
4 \\
5 \\
6 \\
7 \\
8 \\
9 \\
10 \\
11 \\
12 \\
13 \\
14 \\
15 \\
16 \\
17 \\
18\end{array}$ & $\begin{array}{r}39 \cdot 6 \\
63 \cdot 0 \\
57 \cdot 0 \\
53 \cdot 3 \\
84 \cdot 6 \\
29 \cdot 3 \\
87 \cdot 6 \\
17 \cdot 0 \\
101 \cdot 6 \\
50 \cdot 6 \\
37 \cdot 6 \\
35 \cdot 6 \\
87 \cdot 6 \\
39 \cdot 6 \\
37 \cdot 3 \\
44 \cdot 3 \\
69 \cdot 0 \\
45 \cdot 0\end{array}$ & $\begin{array}{r}195 \\
58 \\
85 \\
97 \\
75 \\
120 \\
200 \\
190 \\
61 \\
69 \\
156 \\
265 \\
62 \\
93 \\
305 \\
81 \\
85 \\
54\end{array}$ & $\begin{array}{r}1 \\
10 \\
11 \\
11 \\
10 \\
8 \\
2 \\
2 \\
10 \\
10 \\
10 \\
7 \\
10 \\
10 \\
8 \\
10 \\
11 \\
11\end{array}$ & $\begin{array}{r}75 \\
525 \\
356 \\
159 \\
870 \\
432 \\
120 \\
463 \\
265 \\
153 \\
728 \\
251 \\
78 \\
639 \\
537 \\
235 \\
216 \\
133\end{array}$ & $\begin{array}{l}25 \cdot 3 \\
57 \cdot 0 \\
77 \cdot 3 \\
58 \cdot 0 \\
51 \cdot 3 \\
46 \cdot 3 \\
30 \cdot 0 \\
12 \cdot 3 \\
76 \cdot 0 \\
67 \cdot 6 \\
38 \cdot 6 \\
32 \cdot 3 \\
76 \cdot 0 \\
34 \cdot 0 \\
37 \cdot 6 \\
63 \cdot 6 \\
45 \cdot 6 \\
60 \cdot 0\end{array}$ & $\begin{array}{r}282 \\
85 \\
91 \\
92 \\
92 \\
90 \\
130 \\
370 \\
69 \\
68 \\
195 \\
240 \\
64 \\
51 \\
170 \\
58 \\
115 \\
55\end{array}$ & $\begin{array}{r}1 \\
10 \\
11 \\
11 \\
10 \\
10 \\
2 \\
2 \\
12 \\
11 \\
10 \\
9 \\
11 \\
11 \\
4 \\
10 \\
11 \\
12\end{array}$ & $\begin{array}{r}14 \\
321 \\
84 \\
45 \\
162 \\
81 \\
146 \\
130 \\
127 \\
201 \\
479 \\
188 \\
14 \\
398 \\
429 \\
46 \\
67 \\
33\end{array}$ & $\begin{array}{l}\text { Haloperidol } \\
\text { Tiapride } \\
\text { Tiapride } \\
\text { Pimozide } \\
\text { Haloperidol } \\
\text { Pimozide } \\
\text { Haloperidol } \\
\text { Pimozide } \\
\text { Pimozide } \\
\text { Tiapride } \\
\text { Pimozide } \\
\text { Tiapride } \\
\text { Pimozide } \\
\text { Pimozide } \\
\text { Tiapride } \\
\text { Pimozide } \\
\text { Haloperidol } \\
\text { Haloperieol }\end{array}$ & $\begin{array}{l}\text { Akinesia, rigidity } \\
\text { Depression } \\
\text { Somnolence } \\
\text { Dysarthria }\end{array}$ \\
\hline
\end{tabular}

${ }^{*}$ Treatment which best reduced abnormal involuntary movements. tp $<0.001$.

also lower in Huntington's disease patients than in control subjects.

Pimozide and haloperidol reduced abnormal involuntary movements but did not modify any of the motor performance test results. Tiapride had no effect on abnormal involuntary movements or motor dexterity (table 3 ).

For each patient, the treatment which best reduced abnormal involuntary movements (best treatment) was considered (table 4). A comparison between the basal condition and the best treatment condition showed that only abnormal involuntary movements were improved by neuroleptic treatment, whereas none of the motor performance tests was modified by neuroleptic treatment (table 4). In the best treatment condition, there was a correlation among motor performance test scores; the WAIS score also correlated with the tapping test score (table 2), whereas no correlation was found between abnormal involuntary movements score and the WAIS score or between the former and motor performance test scores (table 2).

Side effects for each patient during the best treatment condition are reported in table 4 . Patient no 9 complained of lightheadedness and patient no 11 of somnolence during treatment with haloperidol; patient no 5 reported somnolence during treatment with tiapride.

\section{Discussion}

Evaluation of the results obtained at basal condition confirmed the overall intellectual deterioration of the choreics ${ }^{112}$ and the impairment of motor abilities which required the execution of rapid sequences and visuomotor coordination. ${ }^{13}$ The correlation between the WAIS score and the screw-and-nut test score, and between the screw-and-nut test score and the Gibson score, suggests that cognitive functions and motor dexterity functions may deteriorate at the same time in the established form of Huntington's disease, in relation to the diffuse neuropathological damage of the basal ganglia and the cerebral cortex. ${ }^{14}$

The lack of a correlation between motor performance and abnormal involuntary movements showed that the impaired ability to execute complex movements was not related to the severity of abnormal involuntary movements but was a separate and peculiar aspect of the disease. It may therefore be suggested that the overall severity of Huntington's disease is better depicted by intellectual deterioration and motor disorganisation than by the severity of abnormal involuntary movements. This is in agreement with the observation of Shoulson, ${ }^{79}$ who described a reduction in abnormal involuntary movements and a loss of functional capacities with progression of Huntington's disease.

Only pimozide and haloperidol reduced abnormal involuntary movements; haloperidol was slightly less effective. Since the dosages of haloperidol that inhibit apomorphine-induced behaviour and stimulate striatal levodopa synthesis in animals are a half to a third those of pimozide, ${ }^{2}$ in our opinion, the lower dosage of haloperidol cannot account for the difference in efficacy. Rather, the smaller number of haloperidol-treated patients may have biased the statistical evaluation. 
At the dosages employed, tiapride did not reduce abnormal involuntary movements in our patients. Experimental data show that tiapride is able to inhibit pharmacologically induced motor hyperactivity in animals, but it is not effective in causing cataplexy, thus differing from traditional neuroleptics. ${ }^{15}$ In our opinion, this does not account for its weak efficacy upon choreic hyperkinesia. It is likely that a higher dosage might be as effective as pimozide and haloperidol. However, this needs clarification, since the dosage we employed was in the same range commonly reported as effective. ${ }^{1617}$

There was a lower incidence of side effects during treatment with tiapride, and less with pimozide, compared with treatment with haloperidol. On the whole, our data are in agreement with previous reports $^{34}$ on the efficacy of neuroleptics on choreic hyperkinesia as shown by the data in table 4 , which demonstrate that neuroleptics are highly effective on hyperkinesia, although they do not modify motor performance. Furthermore, in the best treatment condition, the correlation among motor performance tests is much better than in the basal condition, whereas a lack of a correlation between abnormal involuntary movements and motor performance tests is confirmed. In our opinion, the neuroleptic-induced reduction in abnormal involuntary movements may have uncovered a concealed choreic akinesia that was responsible for the impairment of relatively simple, ballistic movements like tapping ${ }^{18}$ and more complex movements like those in the screw-and-nut test and the Gibson test,$^{10}$ which require visuospatial integration.

The global motor impairment in Huntington's disease parallels the extensive neuropathological damage that involves the basal ganglia and the frontal cortex. Impairment of repetitive ballistic movement is probably due to basal ganglia damage, whose main function appears to be the automatic execution of acquired motor plans. ${ }^{19}$ In contrast, the impairment in the execution of complex motor sequences in Huntington's disease ${ }^{8}$ is similar to that described by Luria ${ }^{20}$ in frontal lobe lesions and points to an involvement of the frontal-motor areas, which are fundamental to motor programming. ${ }^{21}$ Choreic akinesis is an expression of this global impairment of movement and is present at all stages of the disease. It may even become worse with neuroleptic therapy, as was found in our series (table 4-patient nos 1, 8 and 17). It is clear that neuroleptic therapy is not indicated in these patients, whose main symptom is akinesia and who may be evolving to the rigid stage of the disease.

The authors thank Ms B Johnston for editing and preparing the manuscript. The study was partially supported by a grant from FIDIA Research laboratories, Abano Terme (Padova), Italy.

\section{References}

' Marsden CD. Neurotransmitters and CNS disease. Basal ganglia disease. Lancet 1982;2:1141-47.

${ }^{2}$ Carlsson A. Mechanism of action of neuroleptic drugs. In: Lipton MA, Di Mascio A, Killam KF, eds. Psychopharmacology: A Generation of Progress. New York: Raven Press, 1978:1057-70.

${ }^{3}$ Klawans HL, Weiner WJ. Textbook of Clinical Neuropharmacology. New York: Raven Press, 1981:37-47.

${ }^{4}$ Fahn S. Treatment of choreic movements with perphenazine. Adv Neurol 1973;1:755-63.

${ }^{5}$ Caraceni T, Calderini G, Consolazione A, et al. Biochemical aspects of Huntington's chorea. J Neurol Neurosurg Psychiatry 1977;40:581-7.

- Caraceni T, Giovannini P, Girotti F, Avanzini G. Pharmacology of Huntington's chorea. Personal experience. Eur Neurol 1977;16:42-50.

' Shoulson I. Huntington's disease: functional capacities in patients treated with neuroleptic and antidepressant drugs. Neurology (NY) 1981;31:1333-35.

${ }^{8}$ Girotti F, Sghirlanzoni A, Massetto N, Caraceni T. Comparative neuropsychological study of the changes in different programmed activities in subjects with frontal or retro-rolandic lesions or with Huntington's chorea. Encéphale 1978;4:371-81.

${ }^{9}$ Shoulson I. Care of patients and families with Huntington's disease. In: Marsden $\mathrm{CD}$ and Fahn S, eds. Movement Disorders. London: Butterworths International Medical Reviews, 1982:277-90.

${ }^{10}$ Pattie AH, Gilleard CG. A brief psychogeriatric assessment schedule. Br J Psychiatry 1975;127:489-93.

"Norton JC. Patterns of neuropsychological test performance in Huntington's disease. J Nerv Ment Dis 1975; 161:276-9.

12 Fedio P, Cox CS, Neophytides A, Canal-Frederik G, Chase TN. Neuropsychological profile of Huntington's disease: patients and those at risk. Adv Neurol 1979; 23:239-55.

${ }^{13}$ Wexler NS. Perceptual-motor, cognitive and emotional characteristics of persons at risk for Huntington's disease. Adv Neurol 1979;23:257-71.

14 Bruyn GW. Huntington's chorea. In: Winken PJ and Bruyn GW, eds. Handbook of Clinical Neurology, vol. 6. Amsterdam: North Holland, 1968:298-378.

is Jenner P, Marsden CD. The mechanism of action of substituted benzamide drugs. In: Spano PF Traducchi M, Corsini GU, Gessa GL, eds. Sulpiride and Other Benzamides. Milan: Italian Brain Research Foundation Press, 1979:119-47.

16 Trillet M, Joyeux O, Masson R. Tiapride et mouvements anormaux. Sem Hôp Paris 1977;53:21-7.

${ }^{17}$ Emile J, Bastard J, Truelle JL. Utilisation du tiapride en neurologie. Resultats préliminaires. Sem Hôp Paris 1977; 53:16-20. 
${ }^{18}$ Perret E, Eggenberger E, Siegfried J. Simple and complex finger movement performance of patients with Parkinsonism before and after a unilateral stereotaxic thalamotomy. J Neurol Neurosurg Psychiatry 1970;33:16-21.

${ }^{19}$ Marsden CD. The mysterious motor function of the basal ganglia: The Robert Wartenberg Lecture.
Neurology (NY) 1982;32:514-39.

${ }^{20}$ Luria AR. Higher Cortical Functions in Man. London: Tavistock Publications, 1966.

21 Roland PE, Larsen B, Lassen NA, Skinhøj E. Supplementary motor area and other cortical areas in organization of voluntary movements in man. $J$ Neurophysiol 1980;43:118-36. 